\title{
The Future of 4D Subsurface Modelling: Reflections from a Multi-Sector Conference
}

Glen Burridge, Glen Burridge \& Associates

Thomas Finkbeiner, King Abdullah University of Science and Technology

Joerg Herwanger, MP Geomechanics

Wolfgang Hohl, Hohl-Raum

Richard Plumb, Plumb Geomechanics

Katherine Royse, British Geological Survey

John Booth, Geotechnics

Geoff McKinley, Mineral Advisory Pty Ltd

\section{Introduction}

In February this year, the Geological Society of London held a conference entitled $4 D$ Subsurface Modelling: Predicting The Future. Its objective was a novel one: To explore the lessons to be gained by comparing the four industrial geology sectors: Oil \& Gas, Mining, Civil Engineering and Geothermal.

At the heart of this conference lay a question: "If Geoscientists strive for an integrated view of the Earth beneath our feet, why don't we build fully-shared earth models?"

While the construction of elaborate 3D models of the subsurface through time is seemingly commonplace throughout these industries, we wanted to understand what were the driving forces in each industry, what the models are used for and how they are perceived to generate value.

Outputs from the main session talks are supported by the results of several break-out workshops during the event as well as polling of attendees via the Mentimeter smartphone app.

\section{Workshop Outcomes}

The insights gained from this animated and engaging 2-day event (Figure 1) as well as the implications for how Live 3D Models of the subsurface are utilised can be summarized under four principal categories:

\section{Common Concerns across Industries}

- How to assure the quality of the rich variety of inputs that go into these models

- Limitations of 2D screens: We want visualisation which mimics the 4D subsurface

- As complexity grows, capturing and communicating both knowledge and uncertainty

- Powerful standard workflows offer efficiencies, but may stifle creativity:

- Polling results: $75 \%$ of participants believed industries are overly reliant on pre-defined workflows

- Modelling practices need to reconcile deterministic and probabilistic approaches (i.e., hybrid models) within a project.

\section{Learning from Each Other}

- Risk-assuring geomechanics is notably less developed in oil \& gas than other industries.

- Engineering geologists want to help their compatriots, especially in petroleum. These are professional communities that don't often mix. 
- Mining has historically had a sense of inferiority relative to $O \& G$, but in terms of 4D site modelling is progressive in its use of technology and has strong links with civil engineering.

- National surveys have learnt that 3D modelling is their most powerful public communication tool. This is especially important in contested or urban environments.

\section{Barriers to a Coherent \& Integrated 4D Picture}

- Reconciling different modelling components of a model is as much about people and processes as it is about technology

- Insufficient collaboration or understanding between the disciplines building the various components of the model

- Not sufficiently communicating what matters in a model and why may lead to their curtailment as they are no longer useful for decision-making

- Suspicions over the extraordinary complexity of some model-building, especially where multiple versions are created, and the need for distilling down 'knowns'

Figure 2 depicts the results from the Mentimeter poll when workshop attendees were asked "What are the barriers to collaboration?" The word cloud further emphasises the points listed above.

\section{The View of the Ultimate Decision-Makers}

- Senior leaders and investors are primarily driven by how the model will influence their decisions. This will likely boil down to a limited set of critical factors

- Those building the model need to frame the construction of their model to addressing those decision choices. Uncertainty is not necessarily a bad thing, but poor thinking is

- Subsurface modellers need to realise that the model only forms part of a wider picture of value, so the degree of effort expended on it becomes a function of that importance

- Communicating the meaning of a model is ultimately as important as what formed it. That meaning is as much about what is not known as what is
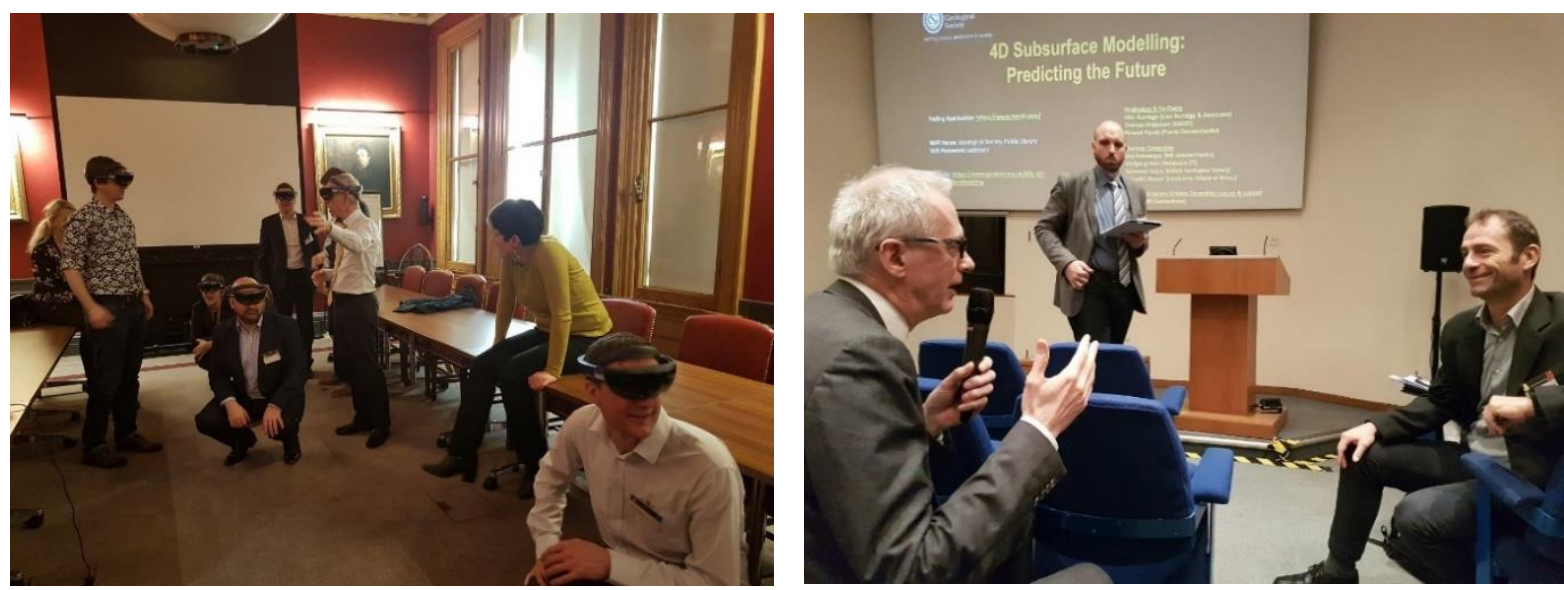

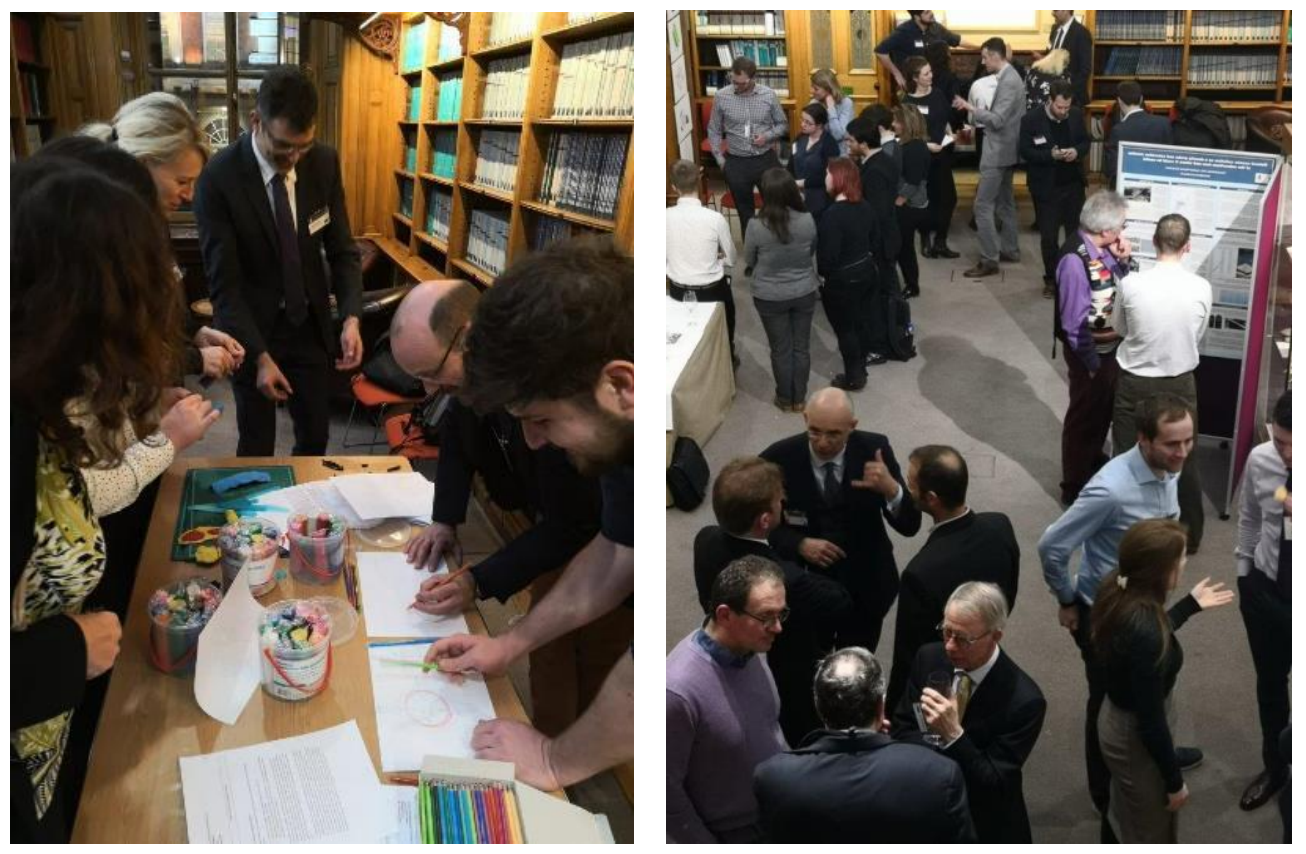

Figure 1 Photos from the presentations, panel discussions, and breakout sessions, which made for a lively and engaging event at the Burlington house of the Geological Society of London.

\section{What are the barriers to collaboration?}

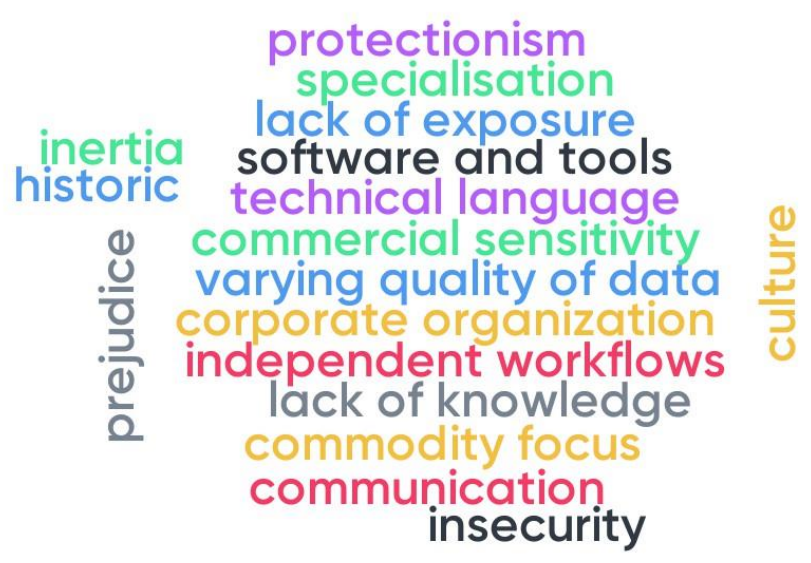

Figure 2 Polling results on the question "What are the barriers to collaboration?" Results are displayed in from of a word cloud, which rearranges itself in real-time to emphasize the most common words submitted by the audience.

\section{Remaining Challenges}

Remaining challenges and questions we would like to pose to the Live 3D modelling workshop are:

- How do we prove 3D/4D modelling is required? What over-arching process decides what information goes into the model?

- How can we make the job of technical decision-makers easier by making what is known/not known more obvious within the model?

- Are experts getting lost in the details and lose track of conveying the important aspects of a 3D model? How do we best communicate across disciplines, up to management and beyond? 
- Is modelling on 2D screens a limitation to critical thinking and communication? The same for over-distilling results in Powerpoint?

- What about presenting inside the model? Either in the software or starting to use 3D holographic tools (e.g. augmented reality) as standard practice?

- How do we encourage and sustain the fruitful dialogue with other industrial sectors with whom we may be able to share unsuspected and fresh insights?

\section{References}

https://www.linkedin.com/pulse/4d-subsurface-modelling-predicting-future-glen-burridge/ https://www.geolsoc.org.uk/expired/GSL-4D-Subsurface-Modelling 